\title{
Bonded anchors in high performance concrete
}

\author{
J. Barnat \& M. Bajer \\ Department of Metal and Timber Structures, Faculty of Civil \\ Engineering, Brno University of Technology, Czech Republic
}

\begin{abstract}
The design of chemical anchor elements presents an ever-topical challenge. Bonded anchors have been in use for many years, but their main field of application is still in concrete with common strength characteristics. This paper summarises the results of experimental and numerical research focused on determination of the behaviour and bond strength limits of what are currently the most widespread industrial glues used for anchor bonding. The goal of this research is to find the limits of the effective use of such glue types in high performance concrete, and also to verify the most commonly used design methods for bonded anchors. The progress and configuration of the experiments are described.

Keywords: bonded anchor, load bearing capacity, bond strength, experiment, tensile load, high performance concrete.
\end{abstract}

\section{Introduction}

The presented research is focused on issues of bond quality and the combined concrete-bond failure of bonded anchors loaded by tensile force. It details an experimental analysis of the glue-concrete interface and the effect of its parameters on anchor behaviour. Usually, in most design approaches the ultimate tensile load-bearing capacity is based on the simplified assumption of separated failure modes. The final design value is covered by a relatively high safety factor. This assumption is also used in certification regulations for post-installed anchors in concrete e.g. the relevant ETAG [1]. The result of the real failure of an anchor loaded by tensile force is shown in Fig. 1 (the failure of the steel anchor bolt is not shown). It is obvious that this failure is influenced by the characteristics of both the concrete and the glue. It is evident from the picture that fully separated failure modes occur only theoretically. A real-life failure will 
only appear similar to a full concrete failure when low strength concrete is used. Also, a real-life failure will only appear similar to a full bond failure when high strength concrete is combined with common industrial glue.

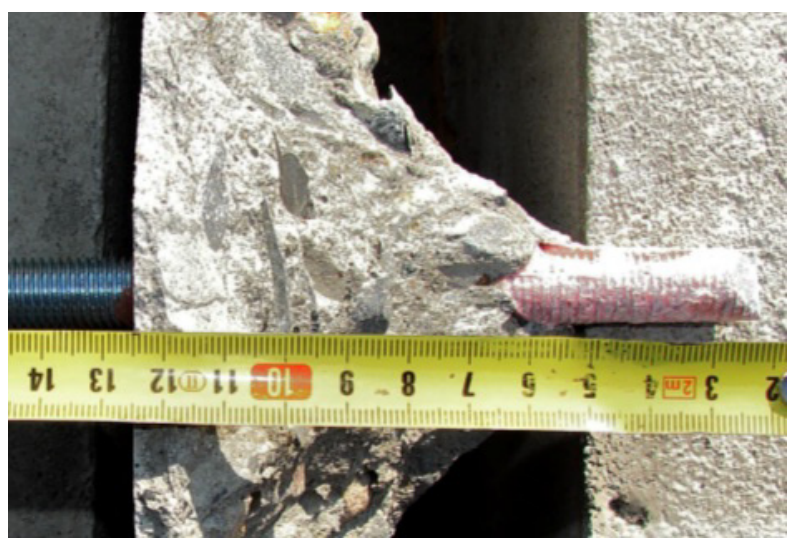

Figure 1: $\quad$ Pull-out test resulting in the concrete-bond failure mode.

\section{Pull out resistance for the combined failure mode}

Problems connected with the combined concrete - bond failure mode are closely described in [2]. The following relation (1) for the tensile resistance of an anchor experiencing the combined concrete-bond failure mode has been published in [2].

$$
N_{u, k}=\pi \cdot \tau_{R k} \cdot d_{o} \cdot h_{e f} \cdot 0.74\left(1-e^{-1.5 \frac{f_{c c, 150, k}}{\tau_{R k}}}\right)
$$

where $N_{u, k} \quad$ is the characteristic tensile anchor resistance,

$h_{e f} \quad$ is the effective anchorage length [mm],

$f_{c c, 150, k}$ is the characteristic compressive concrete strength assessed for $150 \mathrm{~mm}$ cubes $[\mathrm{MPa}$,

$\tau_{R k} \quad$ is the characteristic bond strength, and

$d_{0}$ is the diameter of the drilled hole.

Equation (1) was determined from experimental results (pull-out tests and bond quality tests) for the currently most widely used industrial glues based on vinyl-urethane resin, polymer cement mixtures and epoxy resin. All tests were conducted using common concrete ranging in class from $\mathrm{C} 15 / 20$ to $\mathrm{C} 37 / 45$.

Fig. 2 shows the results obtained by equation (1) for different bond strength values in relation to concrete strength. According to previous experimental results for the bonds provided by currently used glues [2, 3], such bond strengths range from 15 to $20 \mathrm{MPa}$. This bond strength value, together with the standard 
anchorage length, which is about nine times the anchor diameter, ensures the effective utilization of materials with a concrete class of up to C40/50 and a steel bolt quality of 8.8 .

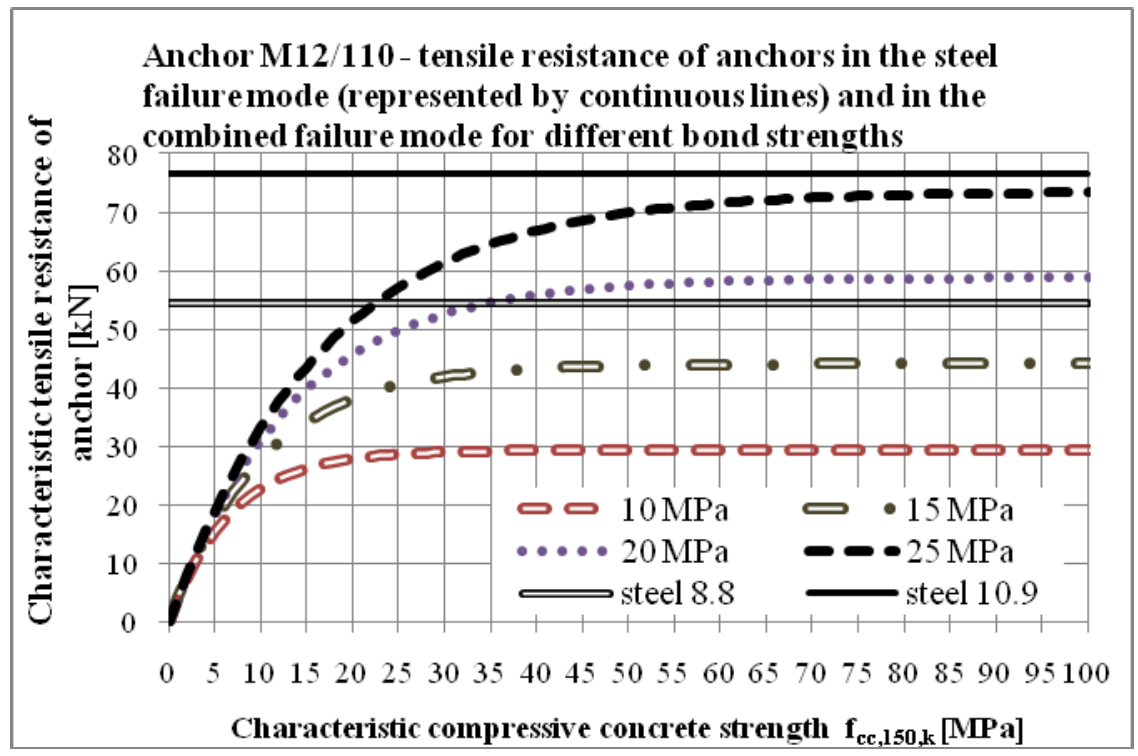

Figure 2: $\quad$ Pull out resistance of anchor according to (1).

For anchoring in high-performance concrete without using extended anchorage lengths it is necessary to also use high strength steel or different materials for the anchor bolts, for example composite fibres. However, the limiting parameter for this kind of anchor application remains the bond strength provided by the glue.

\section{Bond-quality tests}

The experiments described in this paper were focused on the determination of the bond strength of epoxy resin-based glues in concrete with a compressive strength exceeding $40 \mathrm{MPa}$. Originally, the testing of three concrete classes (C40/50, $\mathrm{C} 45 / 55$ and $\mathrm{C} 50 / 60$ ) was planned as a continuation of the experiments described in [2], where concretes ranging in class from $C 20 / 25$ to $C 35 / 45$ were used. The results of laboratory concrete strength tests proved that the mean values of the concrete mixtures were $71.8 \mathrm{MPa}, 82.1 \mathrm{MPa}$ and $80.7 \mathrm{MPa}$. 6 cubes were tested for each mixture. All three mixtures fulfil the criteria for $\mathrm{C} 55 / 67$ concrete. The characteristic values evaluated according to the relevant Eurocode were 67.9, 76.2 and $72.0 \mathrm{MPa}$, respectively. One of the highest quality available glues based on epoxy resin (HILTI HIT-RE500) was tested, together with two experimental epoxy glues, EXP2012/1 and EXP2012/2. The main principle of the bond quality test used (as depicted in the schematic diagram in Fig. 3) is to restrict bond failure 
to the anchor only. Load is applied to the anchor bolt by the loading mechanism which is itself supported by the concrete in the immediate vicinity of the installed anchor. The bond strength is defined as the peak value of the shear stress on the selected interface.
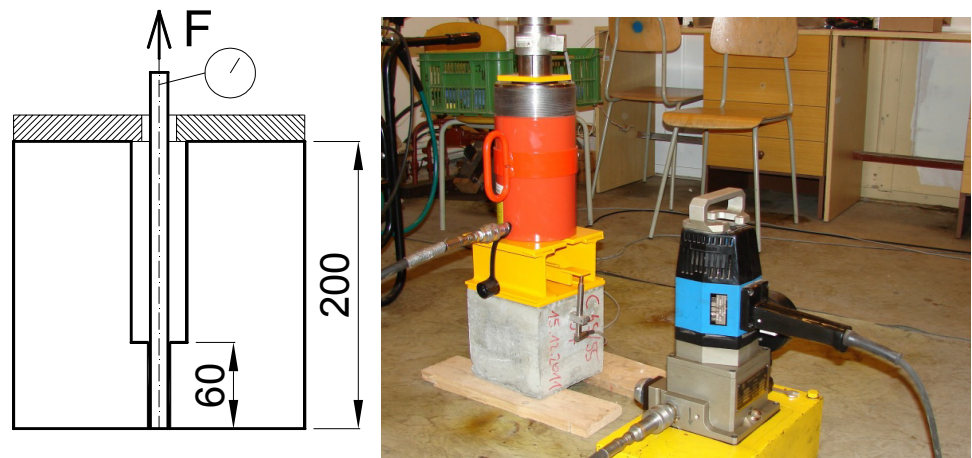

Figure 3: Diagram and photograph of the bond test setup.

All concrete specimens were tempered at $15^{\circ} \mathrm{C}$ for several days. Also anchor installation and glue hardening process was accomplished at the same laboratory temperature. Hardening time, for all specimens was set to 72 hours to ensure full mechanic parameters of hardened glue.

Next three graphs (Fig. 4 - Fig 6) show the working diagram obtained by experiments. Glues were tested on three specimens from each concrete mixture. Graphs show results for all concrete mixtures together. Peak values of bond strength of glues (determined as average value from all tests) are shown in Fig. 7. Results for HILTI HIT-RE500 in dependence on concrete strength are shown in Fig.7. There are also results of older experiments in common concrete class presented in this graph [2].

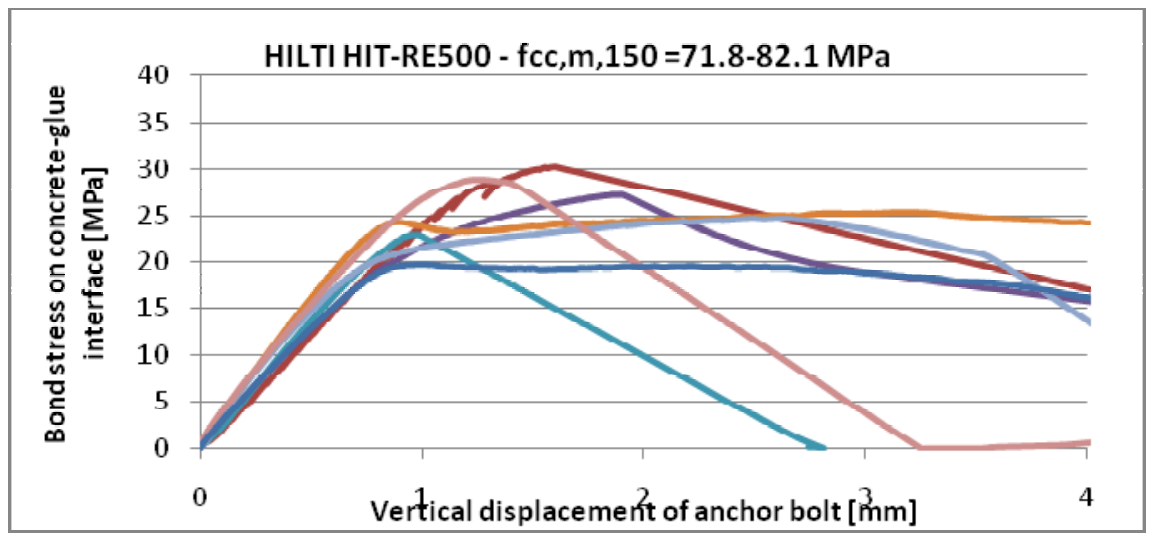

Figure 4: $\quad$ Bond tests - RE500. 


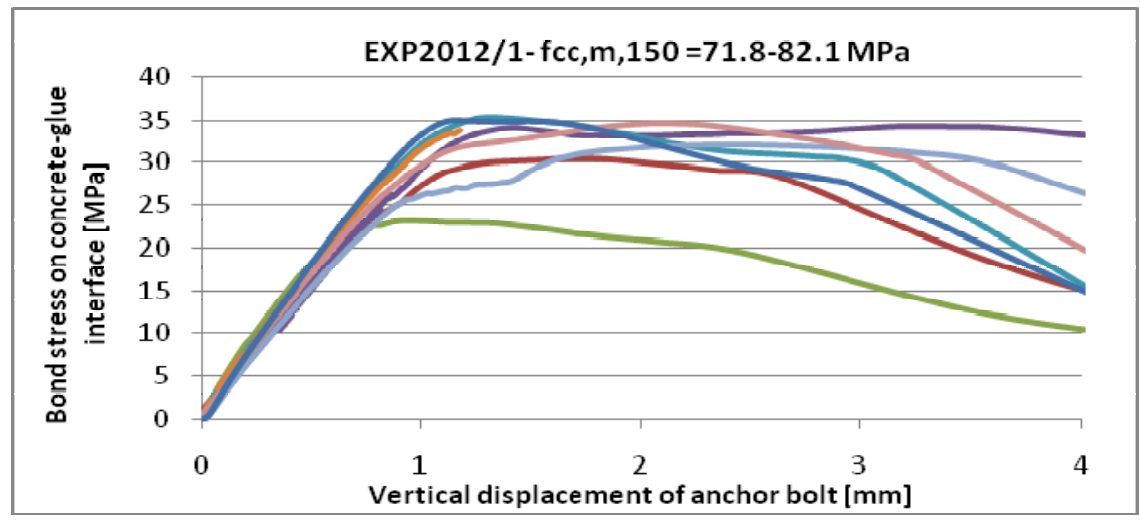

Figure 5: $\quad$ Bond tests - EXP2012/1.

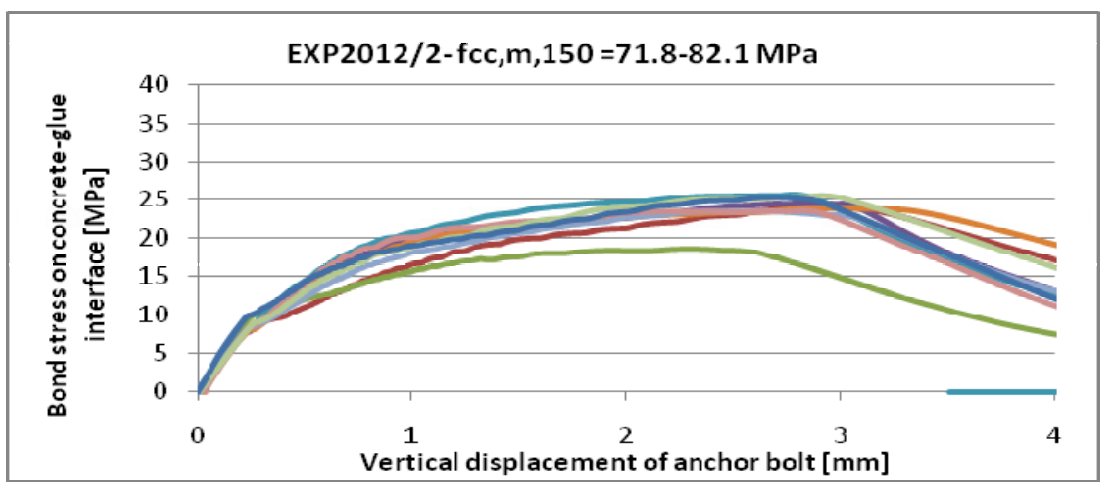

Figure 6: $\quad$ Bond tests - EXP2012/2.

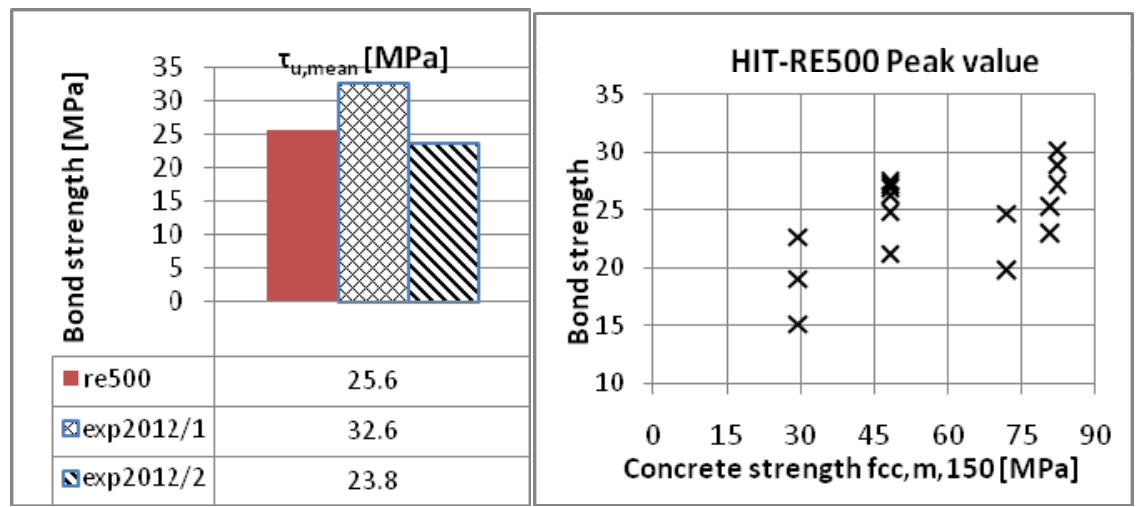

Figure 7: a) Mean bond strength values for three glue types b) Peak bond strength values for HILTI HIT-RE500 glue. 


\section{Conclusion}

Fig. 8 shows three representative specimens after failure occurred during the tests. The results presented in Fig $7 \mathrm{~b}$ show that the bond strength of the tested glues is not dependent on concrete strength exceeding $40 \mathrm{MPa}$. Also, it is possible to designate failures such as those in Fig. 8 as glue failures. Analysis of the results presented in this paper has confirmed that the characteristics of glue are the limiting factor for chemical anchoring in high performance concrete. Therefore, the goal for further research is to modify the composition of glues to achieve improved mechanical characteristics suitable for use in high performance concrete.
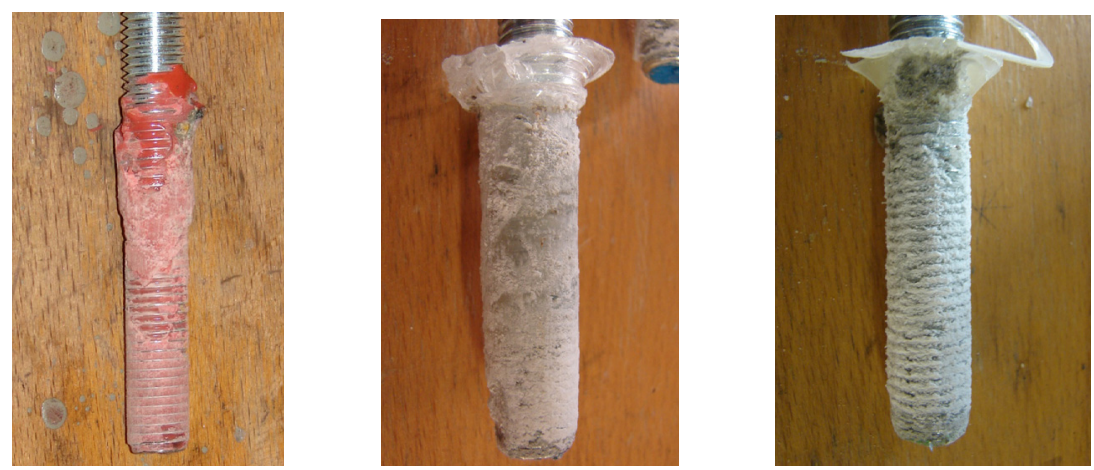

Figure 8: $\quad$ Specimens after failure - RE500; EXP2012/1; EXP2012/2.

\section{Acknowledgements}

This paper was elaborated within the framework of research project GACzR P104/11/P737 and with the financial support of the European Union's "Operational Programme Research and Development for Innovations", No. CZ.1.05/2.1.00/03.0097, as an activity of the regional Centre AdMaS "Advanced Materials, Structures and Technologies".

\section{References}

[1] ETAG 001 Anchoring design methods, EOTA-European Organisation for Technical Approvals, Avenue des Arts 40, Kunstlaan, 1040 Brussels, 2006.

[2] Barnat. J, Behaviour analysis of steel bonded anchors, Ph.D. Thesis, pp. 1618, ISSN 1213-4198, ISBN 978-80-214-4162-0, Brno University of Technology, Faculty of Civil Engineering, 2010.

[3] Cook, R. A., Bishop, M.C., Hagedoorn, H. S., Sikes, D., Richardson, D. S., Adams, T. L. and De Zee, C. T., Adhesive bonded anchors: Bond properties and effects of in service and installation conditions. Report No. 94-2A, University of Florida, Department of Civil Engineering, College of Engineering, Gainsville 1994. 